\title{
Research on the Present Situation and Problems of the Allocation of Basic Education Resources in Guizhou Province under the New Population Situation
}

\author{
Hongqiong Zhu ${ }^{a}$, Xiaoqing $\mathrm{Li}^{\mathrm{b}}$ and Yayuan Wang ${ }^{\mathrm{c}}$ and Jie Shi ${ }^{\mathrm{d}}$ \\ GuiZhou University of Finance and Economics, Guiyang 550025, China. \\ a70770023@qq.com, b1031687889@qq.com, c578770922@qq.com, d1124947942@qq.com
}

\begin{abstract}
With the acceleration of urbanization and the implementation of the "comprehensive two-child" policy, the population size and structure of Guizhou Province have undergone great changes. This change will have a great impact on basic education in Guizhou province. This paper analyzes the allocation of basic education resources from two aspects: supply and demand. On the basis of analyzing the supply problems such as insufficient allocation of basic education resources and unbalanced structure in Guizhou province, it is clear that population changes have new demands on education resources. In order to alleviate the contradiction between supply and demand, the paper puts forward corresponding policy suggestions.
\end{abstract}

Keywords: New population situation; basic education; resource allocation.

\section{新型人口形势下贵州省基础教育资源配置现状及问题研究}

\section{朱红琼，李小庆，王雅媛，石杰 \\ 贵州财经大学, 贵州 贵阳 550025}

摘 要：随着城镇化进程加快及 “全面二孩” 政策的实施，贵州省人口规模与结构发生较大的 变化。这种变化将对贵州省基础教育产生较大的冲击。本文从供需两个方面对贵州省基础教 育资源配置进行分析。在剖析贵州省基础教育资源配置总量不足、结构不均衡等供给问题的 基础上, 明确人口变化对教育资源产生新的需求。为缓解供需矛盾, 文章提出相应的政策建 议。

关键词：新型人口形势；基础教育；资源配置

\section{1. 前言}

随着 “全面二孩” 政策的实施和城镇化进程的加快，我国人口规模与结构出现新的发展与变 化, 并对公共服务提出新的需要。而基础教育作为公共服务的一个重要组成部分，人口规模 与结构的变化对教育资源的供给规模与结构配置会产生一定的影响。对于贵州这样的教育发 展相对落后省份而言，所面临的困难与挑战显而易见的。本文通过调查问卷等形式了解贵州 省基础教育资源配置现状，对 “全面二孩”政策下的生育意愿进行调查的基础上，剖析新人 口形势对贵州省基础教育资源提出新的需求，面临新挑战，并形成相应的政策建议。

\section{2. 贵州省基础教育资源配置现状及存在的问题}

近年来，随着贵州省的基础教育事业不断发展，政府在基础教育上的资金投入不断增加，教 育发展在区域之间的差距也不断缩小，但由于教育存量基础较为薄弱、教育资源投入受限于 困难财政，基础教育资源配置总量上的相对不足、发展不平衡的问题仍旧严重。 
2. 1. 规模大幅度增长、总量仍然不足、筹资渠道单一

随着经济的不断增长, 贵州省在教育方面的支出也不断增加, 从财政性教育经费投入情况来 看, 自 1999 年的 29.61 亿元增长到 2016 年的 803.92 亿元, 增长了 26 倍, 以年均 $22 \%$ 的速 度增长; 占财政收入的比重与占财政支出的比重均以 2003 年为分界线, 出现先上升后下降的 反复循环, 但最后的结果都有所增长。占财政收入的比重从 1999 年的 $22.14 \%$ 增加到 2016 年 的 33. 37\%, 占财政支出的比重从 1999 年的 $17.34 \%$ 增长到 2016 年的 18.86\%; 占 GDP 的比重 自 2002 年起均在 4\%以上。以上指标均高于全国对应指标。贵州省在教育投入上加大了力度, 教育取得了较大的成效, 平均教育年限从 2001 年的 6.13 年增加到 2014 年的 8.09 年, 增加 了 1.96 年。

表1 贵州省及全国1999-2016年教育经费投入情况表

\begin{tabular}{|c|c|c|c|c|c|c|c|c|c|c|}
\hline 年份 & & & 川省教育约 & 投入 & & & & 固教育经 & & \\
\hline $\begin{array}{l}\text { 指 } \\
\text { 标 }\end{array}$ & $\begin{array}{l}\text { 绝对 } \\
\text { 值 } \\
\text { (亿元) }\end{array}$ & $\begin{array}{l}\text { 比上一 } \\
\text { 年增长 }\end{array}$ & $\begin{array}{c}\text { 占财政 } \\
\text { 收入比 } \\
\text { 重 }\end{array}$ & $\begin{array}{c}\text { 占财政支 } \\
\text { 出比重 }\end{array}$ & $\begin{array}{c}\text { 占GDP } \\
\text { 比重 }\end{array}$ & $\begin{array}{l}\text { 绝对值 } \\
\text { (亿元) }\end{array}$ & $\begin{array}{c}\text { 比上一年 } \\
\text { 增长 }\end{array}$ & $\begin{array}{c}\text { 占财政收 } \\
\text { 入比重 }\end{array}$ & $\begin{array}{c}\text { 占财政支 } \\
\text { 出比重 }\end{array}$ & $\begin{array}{c}\text { 占GDP } \\
\text { 比重 }\end{array}$ \\
\hline 1999 & 29.61 & - & $22.14 \%$ & $17.34 \%$ & $3.16 \%$ & 2287.18 & $15.88 \%$ & $19.99 \%$ & $17.34 \%$ & $2.53 \%$ \\
\hline 2000 & 34.83 & $17.63 \%$ & $22.76 \%$ & $17.28 \%$ & $3.38 \%$ & 2562.61 & $17.05 \%$ & $19.13 \%$ & $16.13 \%$ & $2.56 \%$ \\
\hline 2001 & 41.13 & $18.10 \%$ & $23.23 \%$ & $14.95 \%$ & $3.63 \%$ & 3057.01 & $19.29 \%$ & $18.66 \%$ & $16.17 \%$ & $2.76 \%$ \\
\hline 2002 & 50.68 & $23.21 \%$ & $24.96 \%$ & $16.00 \%$ & $4.08 \%$ & 3491.40 & $14.21 \%$ & $18.47 \%$ & $15.83 \%$ & $2.87 \%$ \\
\hline 2003 & 66.07 & $30.37 \%$ & $27.92 \%$ & $19.88 \%$ & $4.63 \%$ & 3850.62 & $10.29 \%$ & $17.73 \%$ & $15.62 \%$ & $2.80 \%$ \\
\hline 2004 & 69.24 & $4.79 \%$ & $23.35 \%$ & $16.55 \%$ & $4.13 \%$ & 4465.86 & $15.98 \%$ & $16.92 \%$ & $15.68 \%$ & $2.76 \%$ \\
\hline 2005 & 81.69 & $17.98 \%$ & $22.31 \%$ & $15.69 \%$ & $4.07 \%$ & 5161.08 & $15.57 \%$ & $16.31 \%$ & $15.21 \%$ & $2.76 \%$ \\
\hline 2006 & 103.14 & $26.26 \%$ & $22.98 \%$ & $16.89 \%$ & $4.41 \%$ & 6348.36 & $23.00 \%$ & $16.38 \%$ & $15.70 \%$ & $2.89 \%$ \\
\hline 2007 & 118.78 & $15.16 \%$ & $21.33 \%$ & $14.93 \%$ & $4.12 \%$ & 8280.21 & $30.43 \%$ & $16.13 \%$ & $16.63 \%$ & $3.06 \%$ \\
\hline 2008 & 167.02 & $40.61 \%$ & $24.76 \%$ & $15.83 \%$ & $4.69 \%$ & 10449.63 & $26.20 \%$ & $17.04 \%$ & $16.69 \%$ & $3.27 \%$ \\
\hline 2009 & 230.02 & $37.72 \%$ & $29.51 \%$ & $16.76 \%$ & $5.88 \%$ & 12231.09 & $17.05 \%$ & $17.85 \%$ & $16.03 \%$ & $3.50 \%$ \\
\hline 2010 & 268.03 & $16.52 \%$ & $27.64 \%$ & $16.43 \%$ & $5.82 \%$ & 14670.07 & $19.94 \%$ & $17.65 \%$ & $16.32 \%$ & $3.55 \%$ \\
\hline 2011 & 313.92 & $17.12 \%$ & $23.60 \%$ & $13.96 \%$ & $5.51 \%$ & 18586.70 & $26.70 \%$ & $17.89 \%$ & $17.01 \%$ & $3.80 \%$ \\
\hline 2012 & 386.96 & $23.27 \%$ & $23.53 \%$ & $14.04 \%$ & $5.65 \%$ & 23145.57 & $24.54 \%$ & $19.74 \%$ & $18.38 \%$ & $4.28 \%$ \\
\hline 2014 & 595.41 & $7.58 \%$ & $27.94 \%$ & $16.81 \%$ & $6.43 \%$ & 26420.58 & 7.89\% & $18.82 \%$ & $17.41 \%$ & $4.10 \%$ \\
\hline 2015 & 676.11 & $13.55 \%$ & $29.50 \%$ & $17.16 \%$ & $6.44 \%$ & 29221.45 & $10.60 \%$ & $19.19 \%$ & $16.61 \%$ & $4.24 \%$ \\
\hline 2016 & 803.92 & $18.90 \%$ & $33.37 \%$ & $18.86 \%$ & $6.83 \%$ & 31373.00 & $4.82 \%$ & $19.66 \%$ & $16.71 \%$ & $4.22 \%$ \\
\hline
\end{tabular}

数据来源: 根据 1999-2016 年的《中国人口统计年鉴》、《中国人口和就业统计年鉴》、《中 国统计年鉴》、《贵州省国民经济和社会发展统计公报》计算所得。

在贵州省教育经费大幅度增长的同时, 受约束于财政教育经费的有限性及历史欠账问题, 贵 州省教育存量与全国差距仍较大。且从贵州省内部来看, 教育经费投入有先后之分, 重点不 同、倾斜不一，教育发展呈现不均衡状态。

从基础教育来看，贵州省的基础教育资金投入每年也在不断增加，但基础教育资金总量相对 于全国平均水平而言仍然是不足的。图 1、图 2、图 3 分别就贵州省基础教育中小学、初中、 高中的生均公共财政预算教育事业投入与全国水平进行了比较, 从图中可以看出, 贵州省基 础教育的财政资金投入虽有较快的增长，但生均所占教育经费仍然是低于全国水平。 


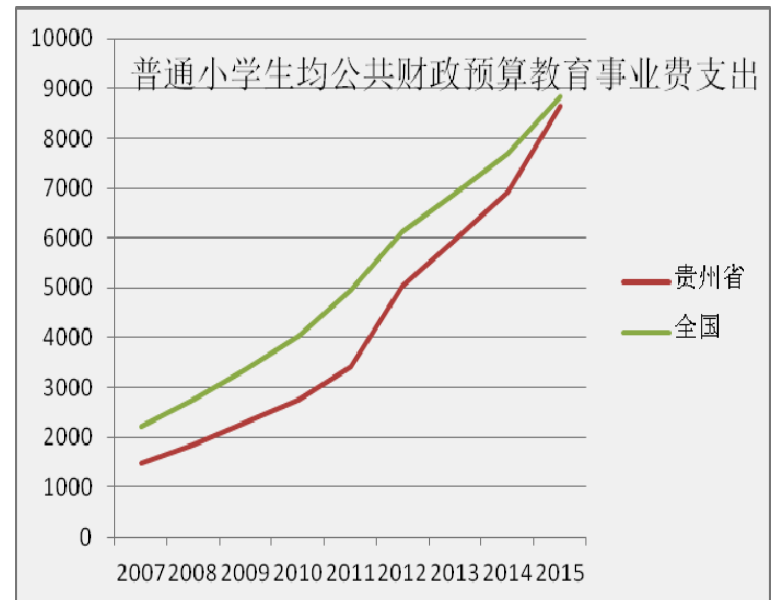

图1 普通小学生均公共财政预算教育事业费支出

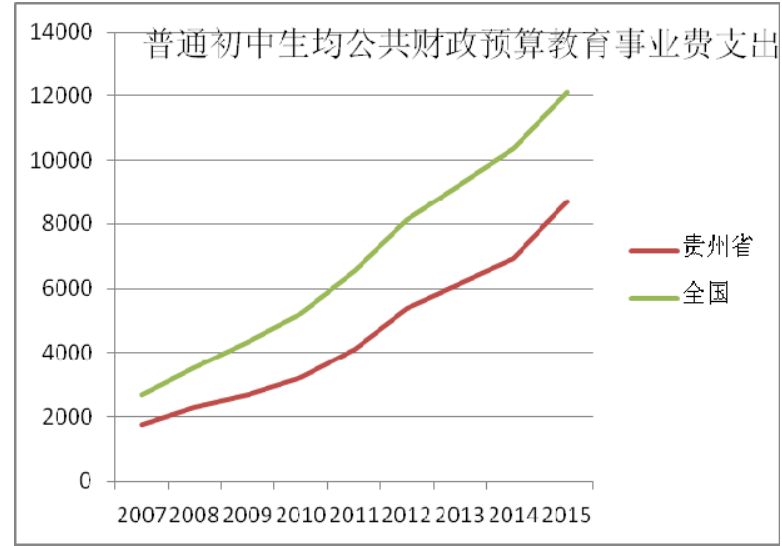

图2 普通初中生均公共财政预算教育事业费支出

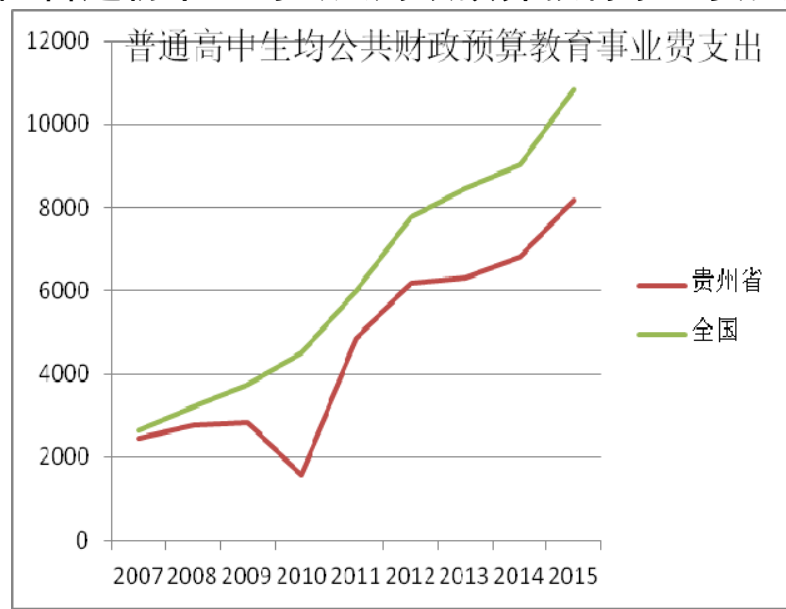

图3 普通高中生均公共财政预算教育事业费支出

整体来看，贵州省基础教育生均教育财政资金的投入低于全国的平均水平，但这种差距在不 同教育阶段表现不一样。与全国平均水平相比, 普通小学生均公共财政预算教育事业费支出 的差距正逐渐缩小, 而普通初中生均公共财政预算事业费支出的差距却有扩大的趋势; 普通 高中生均财政预算教育事业费支出从 2007 年起至 2010 年差距拉大， 2010 年达到最大，此后 有所恢复，但在 2013、2014 年又呈现拉大差距的趋势。

虽然贵州省教育投入有所增长，但教育总体水平与全国的差距还有较大差距。究其原因，教 育资金总量不足，资金渠道单一是影响其教育投入的重要因素。如图 4 所示，近十年来贵州 省教育经费总收入中国家财政性教育经费是最主要的部分, 而民办学校中举办者投入、社会 捐赠、事业收入所占比重较少，教育资金很大程度上依赖于政府财政资金的投入。 


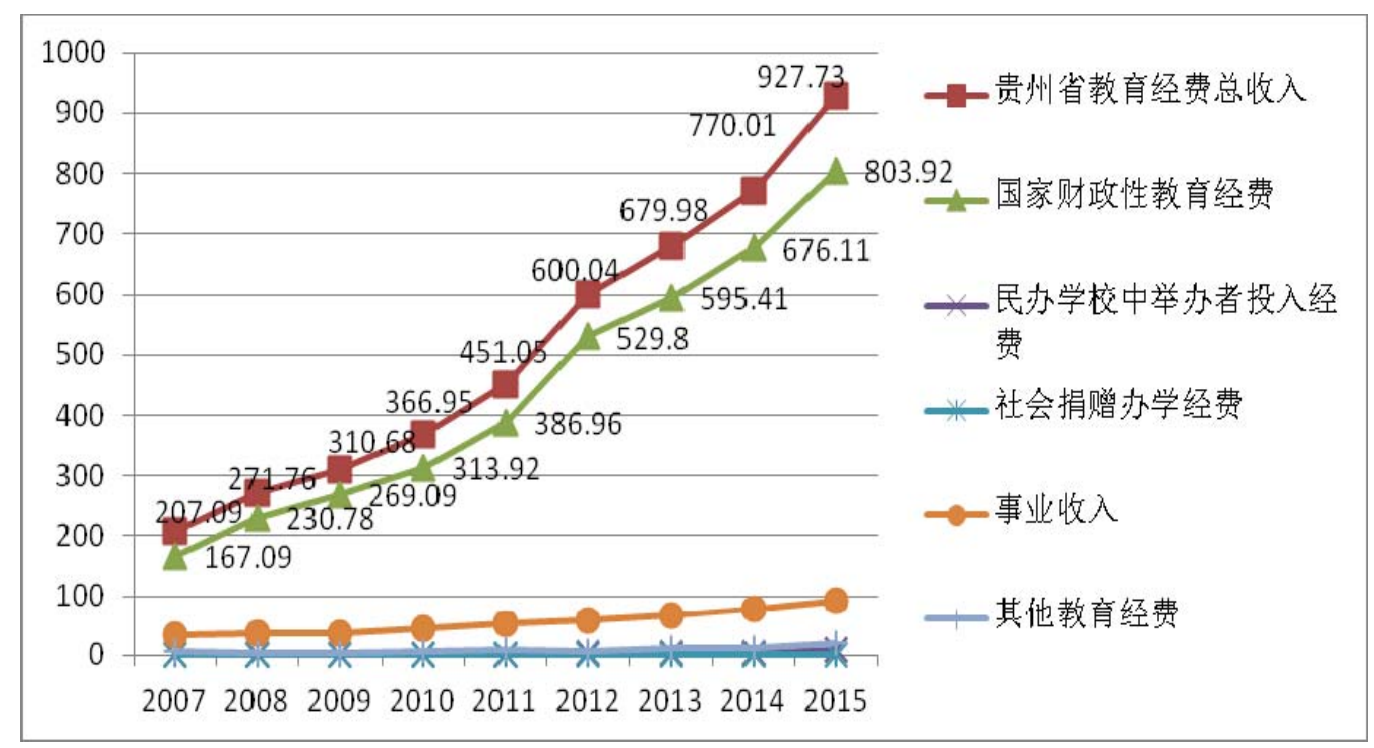

2.2. 地区之间、城乡之间分配不均衡

图4 贵州省教育经费来源结构图

除了总量不足外，贵州省基础教育资源在地区之间分配也不均衡。具体反映在贵州省九个地 州市之间和城乡之间的义务教育生均教育经费投入差距较大。

从贵州省及九个地区 2013 年-2016 年生均教育经费来看, 2013 年至 2016 年，九个地区的生 均教育经费投入差距较大。从小学阶段来看, 四年生均教育经费投入均高于全省平均的地区 有贵阳市、铜仁市、黔西南布依族苗族自治州、黔东南苗族侗族自治州、黔南布依族苗族自 治州, 而其余四个地区则低于全省平均水平。生均教育经费投入 2013-2015 年贵阳市最高, 毕节市最低, 差距分别为 3784.67 元/ 人, 3775.4 元/人, 4087.69 元/人, 2016 年最高的黔 西南布依族苗族自治州与最低的毕节差距为 5075.52 元/人; 从初中阶段来看, 四年生均教育 经费投入均高于全省平均的地区有贵阳市、黔西南布依族苗族自治州、黔东南苗族侗族自治 州、黔南布依族苗族自治州, 铜仁市除 2013 年略低于全省平均水平外, 其余三年均高于全省 平均水平。生均教育经费投入贵阳市最高, 毕节市最低, 2013 年至 2016 年最高与最低之间 的差距分别为 5120.27 元/人、 6058.86 元/人、8063. 23 元/人、 8472.02 元/人。虽然无论是 全省还是九个地区来看, 义务教育生均教育经费投入均有所增加。但由于各地财政投入不一, 使得义务教育阶段的生均经费投入差距日渐拉大。

从城乡之间来看也是如此，贵州省近年来非常重视基础教育的均衡发展，2016 年建立了重在 农村的城乡义务教育经费保障机制, 教育资源在城乡之间的不均衡在逐渐缩小。但由于存量 的原因，贵州省基础教育资源配置在城乡之间的不均衡现象仍然很突出。

从流量来看，每年的生均教育经费投入在城乡之间的差距较大。

表2 贵州省2013-2016年城乡基础教育生均教育经费

\begin{tabular}{ccccc}
\hline 指标 & 2013年 & 2014 年 & 2015 年 & 2016 年 \\
\hline $\begin{array}{c}\text { 初中 (城市) } \\
\text { 初中 (农村) }\end{array}$ & 6210.68 & 6772.77 & 8249.39 & 9905.84 \\
小学 (城市) & & & & \\
小学 (农村) & 6135.61 & 6813.21 & 8589.94 & 9773.55 \\
\hline
\end{tabular}

教师在教育教学中的重要性不言而喻, 从城乡生师比、教师学历结构职称结构来看, 城乡之 间的差距非常明显。 
表3 贵州省2013-2016年城乡基础教育生师比 单位: 学生/教师

\begin{tabular}{ccccc}
\hline 指标 & 2013年 & 2014 年 & 2015 年 & 2016 年 \\
\hline 普通初中 (城市) & 18.52 & 17.45 & 16.11 & 15.07 \\
初中 (农村) & 17.64 & 16.88 & 15.71 & 14.27 \\
普通小学 (城市) & 22.38 & 20.31 & 19.98 & 19.84 \\
小学 (农村) & 17.53 & 15.92 & 15.77 & 15.74 \\
\hline
\end{tabular}

数据来源：根据历年《中国教育经费统计年鉴》中生均教育经费整理所得。

表4 贵州省2016年城乡间初中阶段教师质量对比表

\begin{tabular}{cccccc}
\hline 学历 & 研究生毕业 & 本科生毕业 & 专科毕业 & 高中阶段毕业 & 高中阶段毕业以下 \\
\hline 城市 & 534 & 76425 & 20423 & 192 & 10 \\
农村 & 66 & 22391 & 6972 & 80 & 4 \\
职称 & 中学高级 & 中学一级 & 中学二级 & 中学三级 & 未定职级 \\
城市 & 15908 & 37104 & 30001 & 1503 & 13068 \\
农村 & 3318 & 9450 & 10511 & 932 & 5302 \\
\hline
\end{tabular}

表5 贵州省2016年城乡间小学阶段教师质量对比表

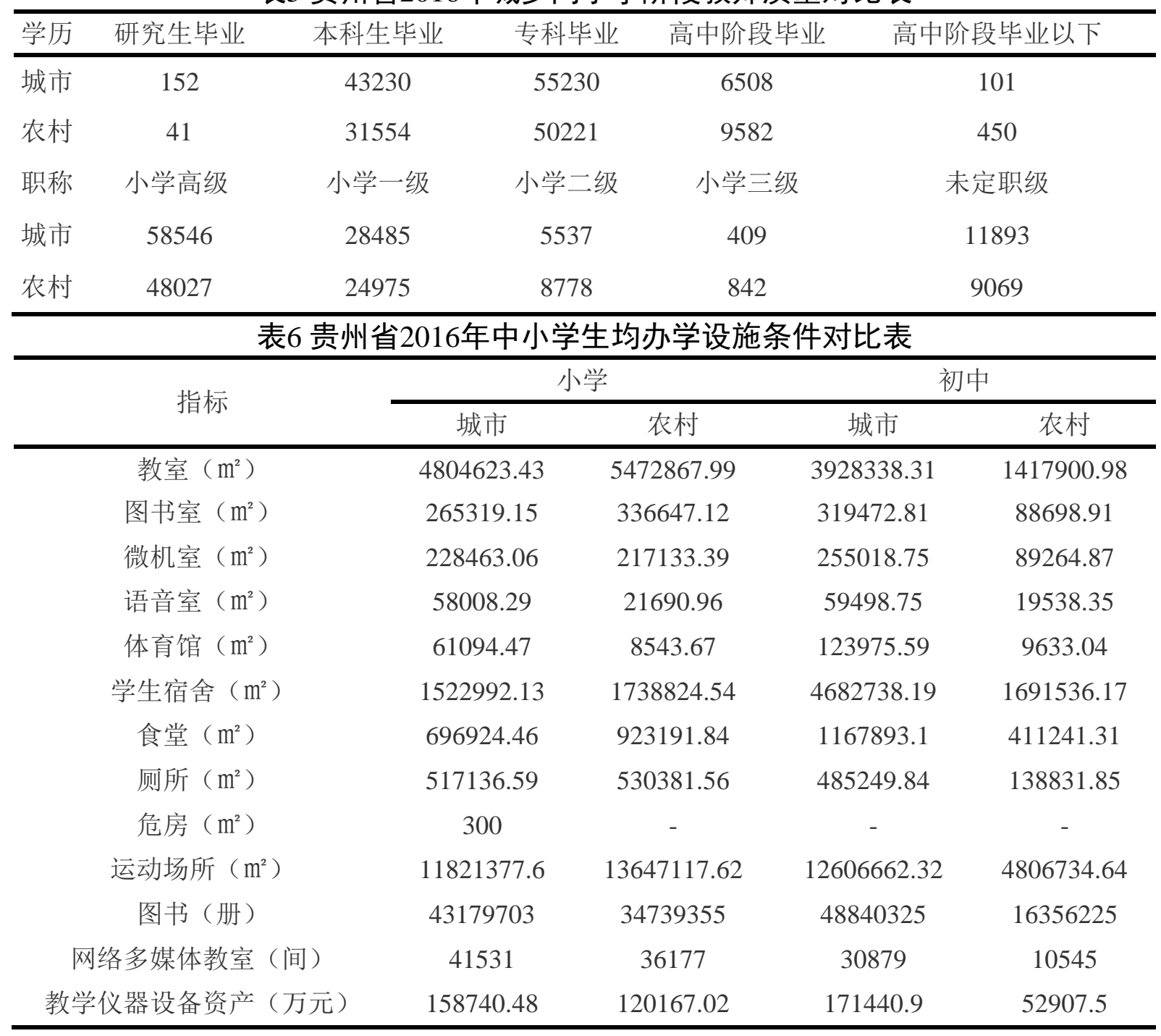




\section{3. 新人口形势下基础教育资源的需求与挑战}

面对的城镇化进程不断加快以及全面二孩政策的提出, 贵州省基础教育资源的需求随之发生 改变, 基础教育的提供迎来新的挑战。

3. 1. 城镇化改变教育需求结构

贵州省城镇化的过程中, 随着人口从农村流向城镇, 适龄儿童是否随同父母一起流向城镇, 会对人口流入地与流出地的教育资源供给产生一定的影响。从贵州省的城镇化率来看, 从 2007 年的 28\%增长到 2017 年的 $46.02 \%$ 。在这一过程中，“流动儿童” 与 “留守儿童” 将是一个长 期存在的社会现象，作为劳动力流入的重点区域如贵阳市，重点要解决的是 “流动儿童” 的 教育问题，而对于劳动力输出的重点区域，如农村，其教育则主要是 “留守儿童” 教育的问 题。从本质上来看, 作为整体组成部分的流动儿童与留守儿童都是受到人口流动而影响的学 龄儿童, 是同一个儿童群体在空间上和家庭形态上差别的体现, 是可以相互转化的, 而变化 的最终去向是由 “留守儿童” 变成 “流动儿童”。“流动儿童” 的 “两为主” 方针，对流入 地 (城镇) 的基础教育投入提出了新的需求。而 “留守儿童” 的特殊性也对农村基础教育提 出新的需求。城镇化率提高较快的前五名分别是贵阳、遵义和黔东南州、六盘水、铜仁。

\section{表7 贵州省2014-2017年城镇化率}

\begin{tabular}{lcc}
\hline 年份 & 常住人口城镇化率(\%) & 比上一年增长 $(\%)$ \\
\hline 2017 & 46.02 & 1.87 \\
2016 & 44.15 & 2.14 \\
2015 & 43.22 & 8.02 \\
2014 & 40.01 & 2.18 \\
\hline
\end{tabular}

3.2. 人口政策增加教育需求

“全面二孩”政策的实行，对贵州省人口增长、人口结构变化毫无疑问有着巨大的影响。表 8 所示的是贵州省各年度人口出生率及其增长速度情况, 从表中可以看出, 自 2010 年以来贵 州省人口出生率开始逐年下降, 至 2016 年开始大幅度上涨。

表8 贵州省各年度人口出生率及其增长速度

\begin{tabular}{lcc}
\hline 年份 & 人口出生率(\%) & 人口出生率增长速度 \\
\hline 2017 & 13.98 & $4.10 \%$ \\
2016 & 13.43 & $3.31 \%$ \\
2015 & 13 & $0.15 \%$ \\
2014 & 12.98 & $-0.54 \%$ \\
2013 & 13.05 & $-1.66 \%$ \\
2012 & 13.27 & $-0.30 \%$ \\
2011 & 13.31 & $-4.66 \%$ \\
2010 & 13.96 & $2.27 \%$ \\
2009 & 13.65 & $1.19 \%$ \\
2008 & 13.49 & $1.58 \%$ \\
2007 & 13.28 & - \\
\hline
\end{tabular}

虽然二孩政策的影响很大，但其主要影响的还是城镇居民的生育意愿。在对总数为 346 户城 镇人口生育意愿调查中显示 (见表 9 ), 单孩家庭中愿意生育二胎的人数占 $53 \%$, 其中年龄在 45 周岁以下的占 $93 \%$ 。 
表 9 城镇人口生育意愿调查

\begin{tabular}{ccc}
\hline & 愿意 & 不愿意 \\
\hline 生育二孩 & $53 \%$ & $47 \%$ \\
\hline
\end{tabular}

在对影响生育意愿的因素调查如下, 居民的生育意愿受多方面因素的影响。其主要因素由强 到弱有工作压力、经济条件、身体状况，教育成本，抚养成本。其中教育成本排在第四位。

表10 影响生育意愿的因素

\begin{tabular}{cc}
\hline 影响生育意愿的因素 & 比例 \\
\hline 身体状况 & $13.69 \%$ \\
工作压力 & $23.65 \%$ \\
经济与居住条件 & $17.84 \%$ \\
抚养成本 & $9.96 \%$ \\
教育成本 & $10.37 \%$ \\
是否有老人帮忙看孩子 & $5.81 \%$ \\
父母、社会的压力 & $4.56 \%$ \\
国家生育政策 & $4.56 \%$ \\
限制自由 & $1.24 \%$ \\
结婚早晚 & $1.24 \%$ \\
社会保障 & $1.66 \%$ \\
其他 & $5.39 \%$ \\
\hline
\end{tabular}

综上可知, 随着二孩政策的放开，生活条件的不断改善，收入的不断提高，越来越多的家庭 家会选择生育二孩, 由此不仅会带来家庭教育成本的增加, 更重要的是学龄儿童数量的增加, 相应的导致教育需求的改变。

教育的对象是人，人口规模和结构决定教育规模和结构，在城镇化和二孩政策的影响下，各 地区的学龄人口的数量也必然随之变化, 不同层次的教育需求在地区之间也会发生相应的变 化。其中, 受影响最大的是基础教育的需求。因此教育规模、教育投资及其配置都应发生相 应的变化。

3. 3. 贵州省基础教育面临的挑战

3.3.1 基础教育各学段学生规模短期扩大

受 “全面二孩” 政策的影响, 贵州省学龄人口数量短期内将会持续增长, 随着时间的延长, 在 2021、2027、2030 年、学前、小学、初中、学龄教育会因为学龄人口数量突然增加而压力 大增。2017 年人口出生率比 2016 年增加 $0.55 \%$ 。假设短期内人口出生率增加速度保持不变, 每年新出生㚣儿将会增加大约 1.4 万人。预测, 2021 年将至少新增 7 万学龄儿童达到小学入 学年龄, 由此, 必然会给基础教育资源配置带来一定的压力, 特别是在短期内学前教育需求 增加。根据 2015 年贵州省统计年鉴数据可知, 2015 年贵州省小学 8520 所, 在校生 3463095 人, 平均每所学校 406 人。以此情况, 在 2021 年大约需要新增 172 所小学, 以满足新增的上 学需求。但政策作用不是长期性的, 当基础教育各学段的在校学生规模达到最高峰值后, 各 学段在校学生数将会不断减少。从长期的变化情况来看, 由于 “独生子女” 政策的惯性作用, 以及各种影响生育意愿因素的影响下, 学龄人口数目又将出现缩小的趋势, 最后稳定在高于 现值的数量。 


\section{3 .2 基础教育各学段经费需求将持续增长}

尽管政策效应时间长短无法确定，但是从长期来看学龄人口的数量是增加的。学龄人口数量 的增加, 不仅对学校数量会差生大的需求, 也会对专任教师数量, 基础教学设备有更大的压 力。教师无论是数量上还是质量上与全国相比还有较大的差距。在新的人口形势下, 要想增 加各种基础教育资源的数量和提高质量, 必然需要增加教育经费投入。

3. 3.3 各地区基础教育需求结构难以预测

基础教育需求结构不仅短期内受到新增学龄人口的影响，城镇化的进行也将会对各地区基础 教育需求结构产生影响。在城镇化不断推进的过程中, 人口流动使得原本区域之间不均衡的 基础教育资源配置，进行公平有效的配置更加难以进行。

\section{4. 政策措施}

通过以上论述, 对贵州省基础教育资源如何配置, 以适应新人口形势的变化, 给出如下建议。 4. 1. 拓宽经费来源渠道，缓解基础教育经费压力

受贵州省经济条件和地理环境限制，贵州基础教育投入成本相对其他省份而言较高。尽管政 府对基础教育资金投入总量不断增加，许多地区的教育投入仍然相对不足。在新形势下，人 口总量不断增加，这无疑会给政府资金投入造成更大的压力。因此，在保持基础教育财政经 费不断增长的同时，还应该拓宽经费来源渠道，增加基础教育资源配置规模。尽管自 1990 年 就出台了《贵州省关于多渠道筹措基础教育经费暂行办法》（以下简称办法），通过税收优 惠等各种措施鼓励社会办学。然而《办法》中涉及范围相对较窄。应当对其进行完善，拓宽 教育资源补助方式, 鼓励多种方式的教育资源捐赠, 如资金、物资, 设备, 人力, 学舍等, 还可以通过招标的方式，吸收社会资金在偏远、教育资源更加贵乏的地区进行办学，同时对 给与帮助或参与投资的个人给与更加优惠的政策。

4. 2. 明确政策作用时限，理性扩充教育资源

“二孩政策”具有时限性，在不同时期它对各个层次的基础教育的影响是不同的，例如在 2021 年学前教育受的影响最大，而随后受到影响的是小学、初中、高中。同时，在不同地区，基 础教育资源配置收到的影响面也是不一样的。应该根据各地区实际情况, 酌情对是师资力量, 硬件设施, 学校数量进行调整。对原本学校分散的地区, 应当使得交通更加便利, 增加教师 数目, 由于上学花费的时间较长, 因为要充分利用县域时间进行教育, 可增加对图书室, 阅 览室的投入。对于教学资源相对密集的城镇来说, 适当增加学校数量。当然, 在扩教育资源 配置的同时, 但也应保持理性, 不能盲目, 避免浪费。要及时了解需求结构, 提前做好应对 措施。

4. 3. 提高质量, 加强中小学教师队伍建设

对农村来说，基础教育设施不全，师资力量不高，是普遍存在的现象。主要是因为城乡之间 的经济差距较大，农村的收入较低，教师工资偏低。首先，应当建立吸引优质教师资源进驻 农村政策。在实施工资补贴的同时推行落实绩效工资，提高基础教育阶段教师工资水平。其 次, 在补充教师资源的同时, 应当定期对教师进行培训, 提高教师的教学能力。最后, 改善 教师生活条件，艰苦边远地区建立教师周转宿舍，使广大农村教师“住有所居”。

4. 4. 调整结构, 协调配置基础教育资源

城镇化引起的人口流动使得基础教育资源在空间上必须进行调整, 避免 “反马太效应” 的产 生造成资源浪费。配置教育资源就是要使教育资源发挥最大效益，在不同的发展阶段、不同 的地方, 可能有不同的衡量标准。首先, 要积极发挥市场的作用, 正确处理政府和市场的关 系, 使市场在资源配置中起决定性作用, 通过市场的竞争机制, 促进基础教育优质均衡发展, 能否促进每个学生全面而充分地发展。其次，间建立更加便捷的需求反应机制。发挥县级政 府在中小学教育中的主体作用, 形成县-镇-乡一体化管理。在充分了解各地区基础教育需求 的同时, 及时制定相应调节政策。最后, 要形成更加有效的教育资金运行监督评价机制, 充 分利用现有教育资源。 


\section{Acknowledgements}

Thanks for Guizhou Department of Education Project Fund (Research on the Supply of Educational Resources in Guizhou Province under the New Population Situation, Project Number: 2016zd04).

\section{References}

[1]. Yao J, Zhu X N. Research on the Effective Allocation of Basic Educational Resources in Medium-and Large-sized Chinese Cities[C]// 2013 international conference on public administration. 2013:2159-2176.

[2]. Jiang T. Research of balanced allocation strategy of basic education informatization resources in Xi'an [J]. China Medical Education Technology, 2013.

[3]. Shen Y L. Research on Fair Allocation of Basic Education Resources [J]. Education Research Monthly, 2009.

[4]. Yao y q. theoretical considerations about the perfect allocation of basic education resources [J]. Journal of Sichuan Teachers College, 2005.

[5]. Zhang X C. Study on Contradictions and Strategies of Rural Physical Education Resources Allocation in the Context of the Basic Education Curriculum Reform [J]. Journal of Beijing Sport University, 2011, 86(7):872-876. 